\title{
Anti-inflammatory activity of ethanol extracts from ready to eat stir-fried chicken with red curry in lipopolysaccharide-induced RAW264.7 murine macrophages
}

\author{
S. Tuntipopipat, C. Muangnoi and P. Chingsuwanrote \\ Institute of Nutrition, Mahidol University, Putthamonthon4, Salaya, Nakhon-Pathom73170, Thailand
}

Phytochemicals in individual spice/herb have been extensively investigated to diminish pro-inflammatory mediator productions ${ }^{(1-4)}$. Pro-inflammatory mediators play biological roles on pathogenesis of several non-communicable diseases ${ }^{(5)}$. Although individual spices/ herbs have been demonstrated to suppress pro-inflammatory mediator productions, investigation of such activity in complex diets has been limited. This study evaluated the anti-inflammatory activity of extract from a popular Thai diet 'ready to eat stir-fried chicken with red curry'. The anti-inflammatory activities of the food extract were evaluated by measuring $\mathrm{NO}_{2}$, iNOS and COX-2 expression in LPSactivated RAW264.7 cells. The mechanism of action was examined by determining the activation of mitogen-activated protein kinases (MAPKs) signalling proteins.

The ready to eat food was prepared by stir-fried less sodium red chilli paste and skinless chicken meat with vegetable oil until cooked. Pea and round eggplants with green peppercorn were added with palm sugar, sorbitol and seasoned with kaffir lime and sweet basil leaves. The food was freeze dried and extracted at ratio $1: 3$ with $90 \%$ ethanol. RAW264.7 cells were cultured in DMEM with $10 \%$ FBS at $37^{\circ} \mathrm{C}$ at $5 \% \mathrm{CO}_{2}$. Cells were pretreated with the ethanol extract of food at $60-240 \mu \mathrm{g} / \mathrm{ml}$ for $1 \mathrm{~h}$ prior to stimulate with LPS for $24 \mathrm{~h}$. Culture medium and cell lysate were collected for measuring $\mathrm{NO}_{2}$ and iNOS, COX-2 and MAPKs protein, respectively. The effects on iNOS and COX-2 mRNA levels were examined by RT-PCR. The food extract significantly suppressed $\mathrm{NO}_{2}$ production (data not shown) and diminished iNOS, COX-2 protein and mRNA levels (Figs 1 and 2, respectively) by dose-dependent without cytotoxicity. It inactivated MAPKs proteins by blocking phosphorylation of p38, ERK1/2 and JNK (Fig. 3) by dose dependent without alteration of total p38, ERK1/ 2 and JNK level.

These results suggested that the ethanol extract from this complex diet containing several spices/herbs possesses high potential to attenuate LPS-induced pro-inflammatory mediators in part by inactivation of MAPKs signalling protein. The health benefit of stir-fried chicken with red curry warrants further investigations in vivo. (Supported by Mahidol University Fund.).
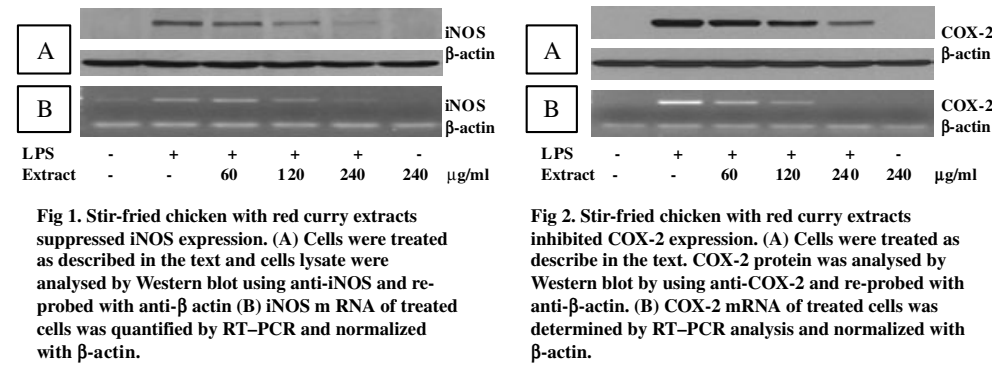

Fig 2. Stir-fried chicken with red curry extracts inhibited COX-2 expression. (A) Cells were treated as describe in the text. COX-2 protein was analysed by Western blot by using anti-COX-2 and re-probed with anti- $\beta$-actin. (B) COX-2 mRNA of treated cells was determined by RT-PCR analysis and normalized with $\beta$-actin.

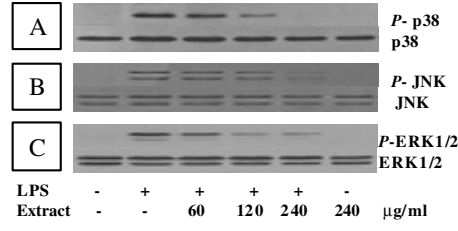

Fig 3. Stir-fried chicken with red curry extracts inhibits MAPKs activation. Cells were treated as described in the text. Cell lysate were reacted with anti-phospho-p38 and p38 antibody (A), antiphospho-JNK and JNK antibody (B) and (C) antiphospho-JNK and JNK antibody (B) and
phospho-ERK1/2 and ERK1/2 antibody.

1. Chainani-Wu N (2003) J Altern Complement Med 9, 161-168.

2. Aggarwal B \& Shishodia S (2004) Ann NY Acad Sci 1030, 434-441.

3. Kaefer C \& Milner J (2008) J Nutr Biochem 19, 347-361.

4. Aggarwal BB \& Shishodia S (2006) Biochem Pharmacol 71, 1397-1421.

5. Aggarwal BB (2004) Cancer Cell 6, 203-208. 